\title{
The 5S and kaizen concept for overall improvement of the organisation: a case study
}

\author{
Shaman Gupta \\ Mechanical Engineering Department, \\ Maharishi Markandeshwar University, \\ Mullana, Haryana, 134003, India \\ E-mail: shamangupta9@gmail.com
}

\section{Sanjiv Kumar Jain*}

Mechanical Engineering Department, Ambala College of Engineering and Applied Research, Devsthali, Ambala, Haryana, 133101, India

E-mail: sk.jain117@yahoo.com

*Corresponding author

\begin{abstract}
The purpose of this study is to implement some of the 5S and kaizen principles to assist small scale manufacturing organisations to become more efficient and more productive. The paper systematically categorises, analyses, and reviews methodically the published literature. In the frames of a case study, the $5 \mathrm{~S}$ and kaizen rules in the organisation have been analysed and implemented. On the basis of the case study, it can be stated that introducing the $5 \mathrm{~S}$ and kaizen rules brings great changes in the organisation, for example, increasing of effectiveness and efficiency in the processes, improved visibility of the process, improved morale and safety of the employees, reduced delays, searching time and dangerous conditions. $5 \mathrm{~S}$ and kaizen is a powerful tool and can be implemented in any industry, whether it is micro, small, medium or large. Implementation of 5S and kaizen has large horizontal development and they can be implemented in all the workstations of the organisation. The $5 \mathrm{~S}$ and kaizen method begins each programme of improvement in a company. Its result is the effective organisation of the workplace. The publications and case study presented in the paper will be useful to researchers, professionals and others concerned with this subject to understand the significance of $5 \mathrm{~S}$ and kaizen.
\end{abstract}

Keywords: 5S; kaizen; continuous improvement; organisational effectiveness.

Reference to this paper should be made as follows: Gupta, S. and Jain, S.K. (2014) 'The 5S and kaizen concept for overall improvement of the organisation: a case study', Int. J. Lean Enterprise Research, Vol. 1, No. 1, pp.22-40.

Biographical notes: Shaman Gupta holds a Bachelor's and Master's in Mechanical Engineering from Kurukshetra University, Kurukshetra, Haryana, India. Currently, he is working as an Assistant Professor in Department of Mechanical Engineering at Maharishi Markandeshwar University, Ambala, Mullana, Haryana, India. His main research area is lean manufacturing. 
Sanjiv Kumar Jain holds a Bachelor's in Mechanical Engineering from The Institution of Engineers, Calcutta, and Masters in Industrial Engineering from Guru Nanak Dev Engineering College, Ludhiana, India. Currently, he is working as an Associate Professor in Department of Mechanical Engineering at Ambala College of Engineering and Applied Research, Ambala, Haryana, India. His main research area is ISO 9000 and lean manufacturing.

\section{Introduction}

- $5 S$ : the $5 \mathrm{~S}$ is the acronym of five Japanese words which stands for Seiri (sorting), Seiton (set in order), Seiso (sweep), Seiketsu (standardise), Shitsuke (sustain) (Ho et al., 1995; Ho, 1997; Vasudevan, 1998). In the mid 1950s, 5S was first used in Japan in the manufacturing sector (Korkut et al., 2009). 5S is the first step to the continuous improvement. $5 \mathrm{~S}$ implementation ensures continuous improvement in housekeeping and results in better environment and safety standards (Ho, 1999a; Mente, 1994). There is need of developing a common language that is understood by all, so that humans can communicate with each other in the company (Sethi and Pal, 1995). However 5S is a practice which can't be implemented without a self discipline (Pheng, 2001). Many problems can be solved by organising the $5 \mathrm{~S}$ team (Ho, 1999b, Ho, 1999c). Organising 5S team will result in maintaining a quality environment in the firm (Hough, 1998; Mente, 1994; Sethi and Pal, 1995). Quality environment includes both order and cleanliness (Pheng and Khoo, 2001; Saraph, 1989). $5 \mathrm{~S}$ becomes more effective when it is integrated to management system (Sevim, 2005). Support from management level is vital to have potential benefits from 5S implementation (Narasimhan, 2009). Homes, schools, communities and workplaces all of them can be improved by $5 \mathrm{~S}$ activities (Gapp et al., 2008). A small company in Taiwan underwent $5 \mathrm{~S}$ activities and improved their overall productivity. Implementing $5 \mathrm{~S}$ brought the plant to a neat and organised state (Gunasekran and Lyu, 1997).

- Kaizen: the concept of kaizen was introduced in Japan in 1950 when the government and management had a feeling that there was a problem in their current management system and a pending labour shortage. The problem was solved with the help of some workforce (Brunet, 2000). Kaizen has become an important part of Japanese manufacturing system and has lent some useful contribution to the manufacturing success (Ashmore, 2001). A kaizen study is structured and focused improvement project using a team which is cross functional to improve a targeted work area in an accelerated timeframe (Farris, 2006). In many Western companies the word kaizen has become more common as it indicates a process of continuous improvement (Chen et al., 2000). The word kaizen is a compound word which involves two concepts, Kai (change) and Zen (good) for better (Palmer, 2001). Kaizen needs attaching great value to the details and common sense to make every employee cleverer in the organisation (Asada et al., 2000; Imai, 1986; Imai, 2008). Kaizen calls for an effort for improvement involving everyone in the industry. Kaizen successful implementation results in healthy atmosphere where everyone in the organisation is aware of key goals, objectives and measure of success. Kaizen is considered to be 
more than just a continuous improvement process as it represents daily struggle occurring in the workplace and the manner in which these struggles can be overcome (Malik and YeZhuang, 2006). Models and theories of change such as theory of structure are being integrated with improvements (Pettigrew, 1990). Initial success of kaizen does not guarantee sustainability, some researchers come with an idea that kaizen events should not be done unless they can done with right intent and activities necessary to sustain results (Friedli, 1999).

Application process of kaizen event basically consists of (Asada et al., 2000; Imai, 2008; Imai, 1996; Kraszewski, 2005; Suzuki, 1993):

1 definition of the area to be improved

2 key problem analysis and selection

3 identification of cause of improvement

4 improving project implementation

5 measuring, analysing and comparison of the results

6 standardise systems.

Kaizen covers many techniques which includes kanban, total productive maintenance, six-sigma, automation, just in time, suggestion system and productivity improvement (Imai, 1986).

\section{Literature review}

\section{$2.15 S$}

1 Seiri (sorting): it is the first ' $\mathrm{S}$ ' and its main focus is to eliminate the unnecessary items from the workplace. Red tagging is done to the items which are unnecessary. The items which are occasionally used are moved to a more organised storage area outside of the work area. Items which are completely unnecessary are disposed (Peterson and Smith, 2001). Sorting helps in eliminating scrap, obsolete jigs and fixtures and also broken tools (Harrington, 2000).Specify the work areas to be evaluated and identify type of items which need to be evaluated. In setting red-tag criteria one should ask the questions. How much is needed? How often is it needed? Is it useful? After all these questions are answered attach the red-tag and decide what actions are to be taken (Dudek-Burlikowska, 2006). Documentation of result is the next process so as to measure the improvements and savings through the process (Lancucki, 2001).

2 Seiton (set in order): "A place for everything and everything in its place" is the phrase well suited for 2nd S (Peterson and Smith, 2001). It focuses on effective storage and segregation of things is done (Harrington, 2000). Activities included in this are labelling each item, use colour for quick identification, store similar items together, and store different items together, putting names and numbers on everything, painting floors, and use of rack or shelf and shadow boards for tools (Dudek-Burlikowska, 2006; Lancucki, 2001). 
3 Seiso (Shine): the third ' $\mathrm{S}$ ' focuses on the cleaning. Daily cleanliness is must to have a better work area. More comfortable and safe workplace is ensured in third ' $\mathrm{S}$ ' (Peterson and Smith, 2001; Harrington, 2000). High quality work is achieved. Clean and organised work area act itself as motivation factor for the employees. Every employee enjoys their work in a clean and healthy environment which raises confidence (Dudek-Burlikowska, 2006). People have to make 3rd 'S' as a habit. They have to do the cleanliness without being told to them. Zone wise responsibilities should be given to the employees. Some standards have to be followed to ensure people do the cleaning effectively (Lancucki, 2001).

4 Seiketsu (standardise): the high standard of workplace organisation can be ensured by standardisation (Peterson and Smith, 2001). Good work standards have to be maintained. McDonalds, Pizza Hut are the best examples of it (Harrington, 2000). To develop the standards employees play a great role in it. Every employee knows his responsibilities and housekeeping duties are performed in a regular routine. Best work practices are carried out and different ways are find out to ensure that everyone carries out their individual activity in their workplace (Dudek-Burlikowska, 2006; Lancucki, 2001).

5 Shitsuke (Sustain): this ' $\mathrm{S}$ ' is considered to be the toughest to implement. Many firms do the $5 \mathrm{~S}$ activities for months. But it becomes very difficult to sustain the activities performed for a longer period of time (Peterson and Smith, 2001). Standards have to be maintained year after year in an effective manner (Harrington, 2000; Dudek-Burlikowska, 2006). Counselling of the employees should be done regularly. Proper discipline should be maintained. Also there should be award and reward system to motivate the employees. It can be a financial gain or formal presentation of a certificate (Lancucki, 2001).

\subsection{Kaizen}

Many industries can benefit from kaizen events because it results in increase of the productivity in the company and also it helps in producing high quality products. Benefits from kaizen activities can be achieved with minimum efforts (Deniels, 1996; Reid, 2006). Kaizen is a term which is widely practised in quality circles and manufacturing sector. It relates to continuous improvement process and idea is to make a process which has no end to make process better. Concept of kaizen is not only limited to manufacturing sector, it has widened its scope to all aspects of business including software and service industry (Suzaki, 1987; Cheser, 1998). Success of kaizen activities performed highly depends upon the contribution of teamwork. Every member's role and responsibility has been described by taking an example of Nissan Motor Plant in UK. Direct contact and communication between the employee and boss is key for successful implementation of kaizen activities in the organisation (Wickens, 1990). Understanding of management philosophy of kaizen is must to sustain in constantly changing environment (Deming, 1995). Kaizen activities can be best performed by the operators because they are experts of shop floor and once they know there is some problem they are the ones who will make an effort to solve the problem. All they need is some sort of right direction to solve the problem (Deniels, 1995). Studying the impact of kaizen activities on human resources is must. There are some variables like attitude towards kaizen events, understanding need of kaizen, skills gained from kaizen event participation which are quite useful to measure 
kaizen impact (Doolen et al., 2003). A framework as a design and assessment tool has been made to make the kaizen programme more effective; framework includes assigning roles for kaizen events, measuring results and sharing lessons learned in the areas of the organisation outside the work processes targeted by kaizen programmes (Eileen et al., 2010). There is need to understand target costing and kaizen costing concept. Target costing is a process of making profit by selling the products at a cheaper rate. Target costing and kaizen costing act as basis for the total life cost management and managing cost throughout the product life cycle (Williamson, 1997). Kaizen event effectiveness is important to measure and there are wide numbers of case studies available which are important means to check its effectiveness. Kaizen benefits include improved quality, reduced cost, improved safety, faster deliveries, increased productivity etc. (Powel, 1999). Kaizen technique has been applied to small sized custom made furniture industry. Brainstorming with employee has been done to identify the various problems. Problems include absence of appropriate methodology to assure quality, disorganised workplace lack of training and poor quality of raw material. Suggestions are made to these problems. The main objective of brainstorming is to develop the product with high quality, high productivity and lower cost (Radharamanan et al., 1996). Kaizen events have been applied to Allied Signal Inc., jet engine manufacturing industry. The main problems found are low production rates and large floor space requirements. Implementation of kaizen activities results in $89 \%$ improvement in work in process $88.5 \%$ increase in productivity and saved floor space area up to $2000 \mathrm{sq} \mathrm{ft}$. (Sheridan, 1997). Poka yoke a kaizen tool has been applied in fuel fitter assembly. Problem of lower production rate and problem of errors at large scale are noticed. After implementing kaizen activities a fall from $50 \%$ to $1 \%$ has been seen in error rate and also production increase about 50\% is noticed (Erlandson et al., 1998). A study has been conducted at Nicholas Foods Manufacturing food products. Problems found in organisation are lack of standard operating procedures, forces and structure. Kaizen events purposed in the organisation improved the work environment by raising the company values. Now there are less quality rejections, there is increase in manufacturing efficiencies and reduction in change over times (Lee, 2000). The Gemba-Kaizen approach has been used in the multinational food company of Mexico to enhance their manufacturing performance (Suárez-Barraza et al., 2012). New united motor manufacturing Inc. (NUMMI) in Fermont, California successfully implemented kaizen approach in terms of its organisational design and knowledge management preconditioners (Watanabe, 2011). Two Mexican small family businesses improved their sales, customer and market share by using the Japanese approach for kaizen (Suárez-Barraza, 2011). Implementing personal kaizen in our daily life can bring incremental change which is very helpful for person to improve their quality of life and health (Bingham, 2011). Individual kaizen were implemented by three persons in their personal life and as a result their quality of life improved up to a great extent (Suárez-Barraza et al., 2013). A study has been conducted in Chinese construction companies, 27 Chinese building professionals from 16 companies were interviewed and it has been found out that different types of activities associated with kaizen have been adopted by Chinese construction firms at the project level (Gao and Low, 2013). Doing survey is very effective means to determine the performance of kaizen practices. In Australian SME's survey has been conducted. Survey highlights some critical success factors which include creating an effective structure, promoting a corporate culture and developing flexibility and speed of response (Gibb and Davies, 1990). CI and innovation practices have been performed in French SME's. Short 
and long term goals, nature of innovative management and the sounds of innovation fall in survey parameters in French SME's (Soderquist, 1996). In a small scale manufacturing company a survey has been conducted which suggest that ideal situation of CI strategy is its integration with the corporate culture (Irane and Sharp 1997). A survey has been conducted in Chinese companies. Survey conducted has to check whether CI helps in getting desired results or not. Survey results suggest that there is great extent of effect on the companies as they achieve all the desired results (Hongming et al., 2000). A comparative survey has been conducted between two countries China and Pakistan. Investigation has been done to check how they are deploying CI practices. Eighteen sets of question have been prepared which were related to organisation in both countries. Survey findings clears that both countries are deploying CI practices but with different proportions (Malik et al., 2007).

\section{Methodology}

The literature has suggested that $5 \mathrm{~S}$ and kaizen if implemented sincerely could result in overall improvement of the organisation. The aim of this research was to assist a small scale industry by using $5 \mathrm{~S}$ and kaizen principles. Till date, xyz industry has been using the good old manufacturing technology. But to stay in the business and respond to the changing environment, the industry has to leave traditional manufacturing technique and there is need to follow new manufacturing technique. There is need for making company competitive enough for survival. There is need to establish the culture of continuous improvement. The activities performed in a company are basically categorised as value added activities (VAA) and non-value added activities (NVAA). The customer pays only for the VAA of the product and not for the NVAA. After extreme brainstorming and a detailed thorough study of the shop floor, it is found that material flow contains various forms of NVAA and that is the reason company urgently needed change in the organisation.

Getting started with an effective event to implement $5 \mathrm{~S}$ and kaizen requires careful planning, design and execution of the business changes needed to achieve the desired improvement goals. Implementation should not begin unless top management is solidly championing the effort with an understanding that many business processes must be changed. The company xyz is selected for case study which is small scale industry located in Ambala, Haryana (India).

Table 1 Observations at the company

\begin{tabular}{ll}
\hline Turnover & 80 lakhs \\
Employees & 11 \\
Organisation & Structured \\
Literature & Not developed \\
Quality systems & ISO certified, not implemented \\
Marketing network & Well developed \\
Customers & Various schools and colleges \\
\hline
\end{tabular}




\subsection{Company profile}

The Company is manufacturing educational equipments of laboratory glassware and research apparatus from neutral glass followed by borosilicate glassware and presently quartz glassware. Looking at the scope in the area of calibration, a company was formed in 2007 as a Calibration Laboratory for weights, micro-pipettes and laboratory glassware to cater to the needs of the customer base in the areas of volume and mass. The lab is equipped with a F1 class Mettler Toledo weights from 1 milligram to 200 gram certified by National Physical Laboratory, New Delhi.

\subsection{Problem identification}

Reports have been issued through the observations made in the production site in order to identify and remove the negativities affecting the quality and they have been presented to the top management. Four methods were used to collect data: direct observation; participative observation; documentary analysis; and semi-structured interviews. Using these four data collection methods, following problems were identified which affects the company's manufacturing system:

1 cannot find things or 'lost' or misplaced material or equipment

2 unavailability of information

3 unorganised work areas and lack of housekeeping

4 too much 'travel distance/time' due to poor lay out on shop floor

5 not doing things right the first time

6 there is a chaotic process throughout the factory.

Figure 1 Methodology flow chart

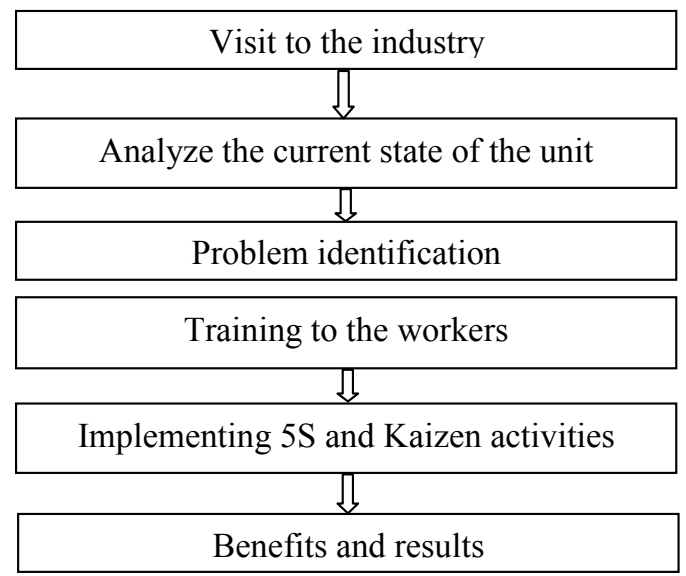




\section{Case study}

\section{$4.15 S$}

\subsubsection{The challenge}

Different sections of organisation were actually used for equipment storage, utility carts, and excess inventory and staff belongings. The question became: how do you organise the different sections of organisation? The answer: conduct a $5 \mathrm{~S}$ event.

\subsubsection{Targets}

The process owner was asked to $5 \mathrm{~S}$ the organisation. There were many things to consider in accepting this challenge, such as: staff morale, search and travel times and how to effectively communicate the changes. Therefore, the $5 \mathrm{~S}$ event targets were established as follows:

- create an organised, usable organisation

- reduce travel time for staff

- $\quad$ reduce supply inventories

- $\quad$ adhere to compliance rules.

\subsubsection{Actions}

\subsubsection{S1 Seiri (sort)}

- $\quad$ unneeded equipments, tools and furniture are held for depreciation or sell

- unneeded inventories, materials or parts are returned to supplier

- $\quad$ garbage present in corners or stairways is discarded or recycled

- red labelling is done to the things not required

- all useless things have been sorted and eliminated.

Figure 2 (a) Unorganised section (before) (b) Organised section (after) (see online version for colours)

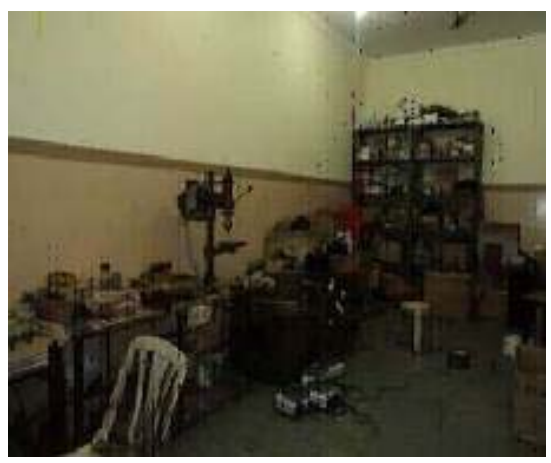

(a)

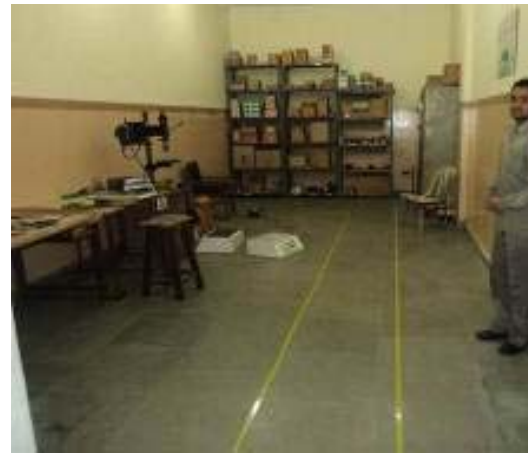

(b) 


\subsubsection{S2 Seiton (set in order)}

- locations of all the objects necessary have been defined and marked

- colours have been used to mark the different areas

- items frequently used are carried on person

- items sometimes used are stored in area close to point of use

- items not used at all are separately stored with identification.

Figure 3 (a) No set in order for items (before) (b) Set in order (after) (see online version for colours)

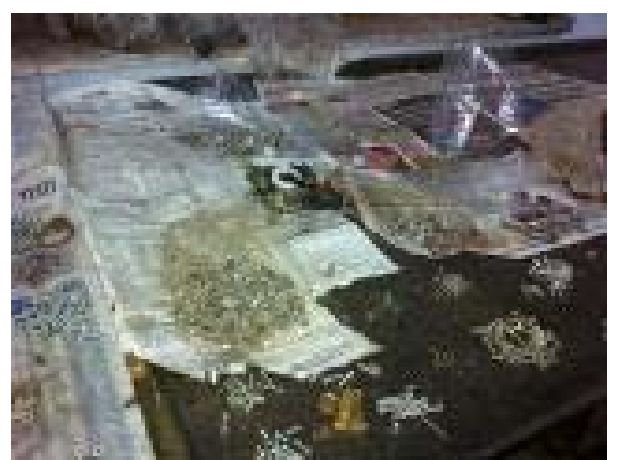

(a)

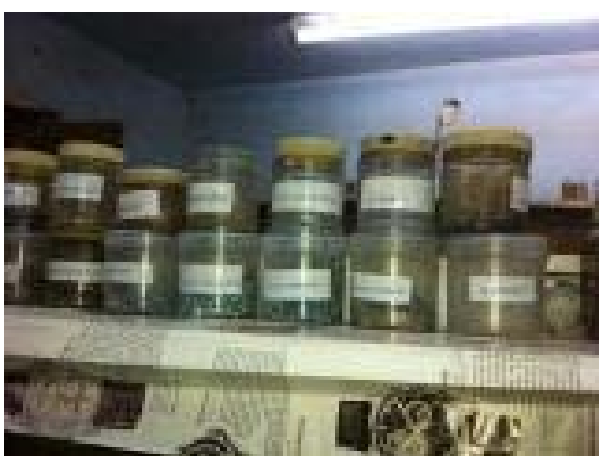

(b)

Figure 4 (a) Tools unarranged (before) (b) Shadow board for tools (after) (see online version for colours)

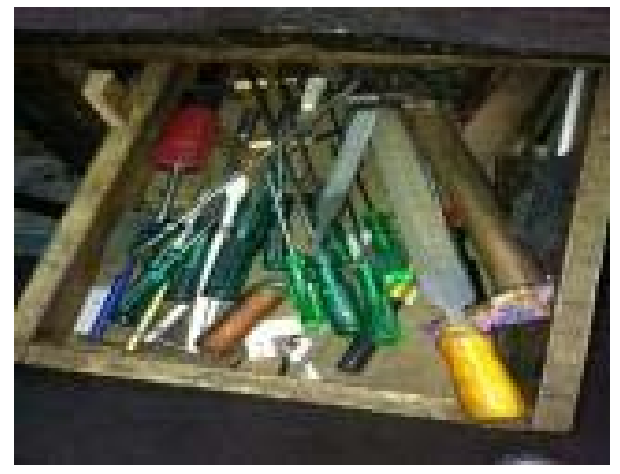

(a)

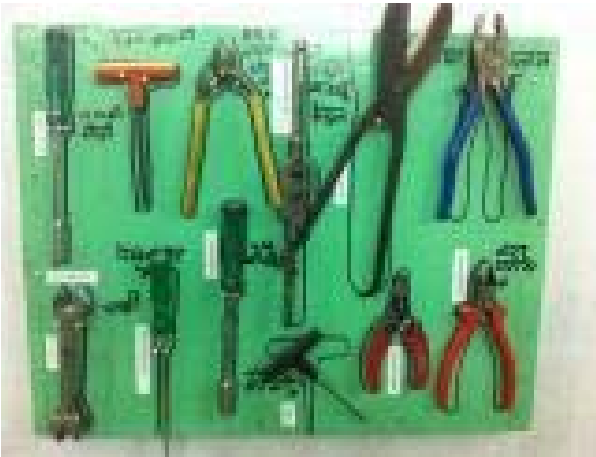

(b)

\subsubsection{S3 Seiso (sweeping)}

- all the machines are clean and free from oil and chips

- floors are clean and free of water 
- $\quad$ person appointed for seeing cleaning operations

- labels and signs are clean and unbroken.

Figure 5 (a) Unclean store (before) (b) Clean store (after) (see online version for colours)

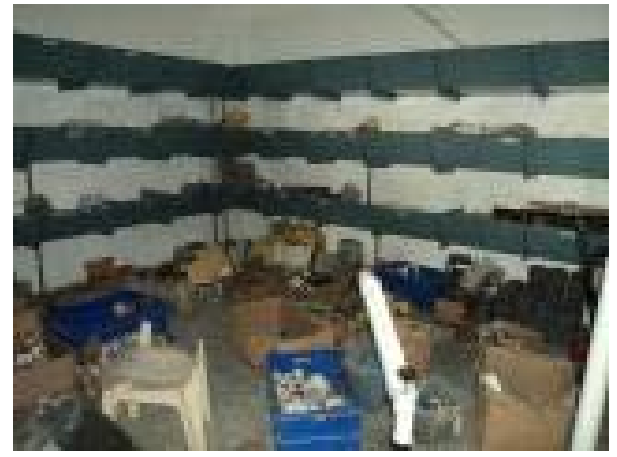

(a)

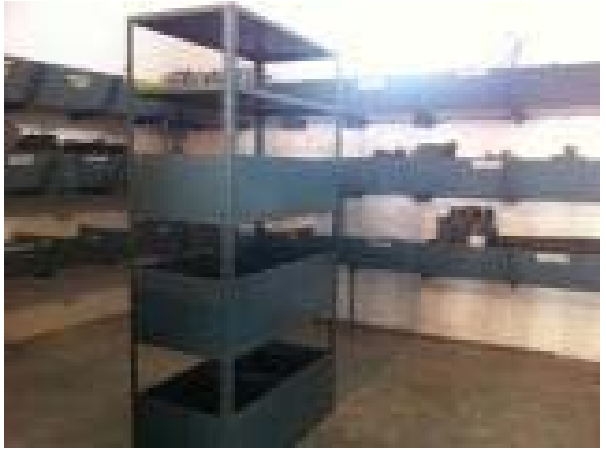

(b)

\subsubsection{S4 Seiketsu (standardise)}

- first three $\mathrm{S}$ has to be maintained

- standard operating procedures should be clear and documented

- work should be done on improvement ideas.

\subsubsection{S5 Shitsuke (sustain)}

- standard procedures are regularly reviewed

- tools and parts are correctly placed

- activity boards are up to date

- need of educating and communicating is must.

- workers need to feel their efforts are recognised and there should be award and reward system.

\section{2 $5 S$ benefits}

Employee learning and participation is first benefit observed when $5 \mathrm{~S}$ is implemented in the organisation (Hubbard, 1999). 5S implementation results in better housekeeping and thereby better visual workplace is observed in the organisation (Cooney, 2002; Becker, 2001). 5S implementation also ensures safer work environment (Chapman, 2005). Reduction in waste, time and cost is another very good benefit of 5S (Hough, 2008). Sharrock (2007) discovered $5 \mathrm{~S}$ implementation results in improved quality, productivity and efficiency. 


\subsection{Kaizen suggestions and implementation}

\subsubsection{Kaizen 1}

- Objective: eliminating the problem of wire melting in the heating mantle equipment.

- Problem: in the heating mantle equipment, wire inside the box melted due to rise in temperature resulting in chances of the short circuit.

- Problem analysis: it was found that the heating mantle equipment was full with the complaints from customer feedback form. They were complaining about the rapid failure of the equipment with few uses.

- Root cause: they were using the Teflon wire without any precautions.

- Action: now they started to use copper wire instead of Teflon wire. They started to cover the copper wire with ceramic (insulating material) material bits for precaution of short circuit.

- Benefits: less failure of the equipment, safety for the worker as well as user increases, High heating capacity of the wires and no melting of wires so no short circuiting.

Figure 6 (a) Teflon wire (before) (b) copper wire (after) (see online version for colours)

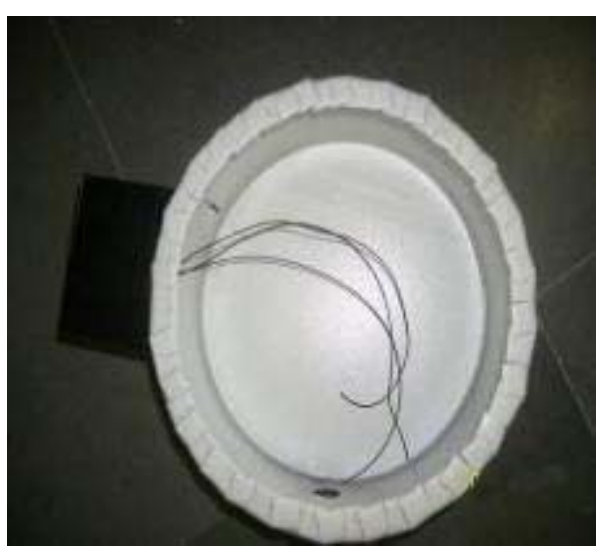

(a)

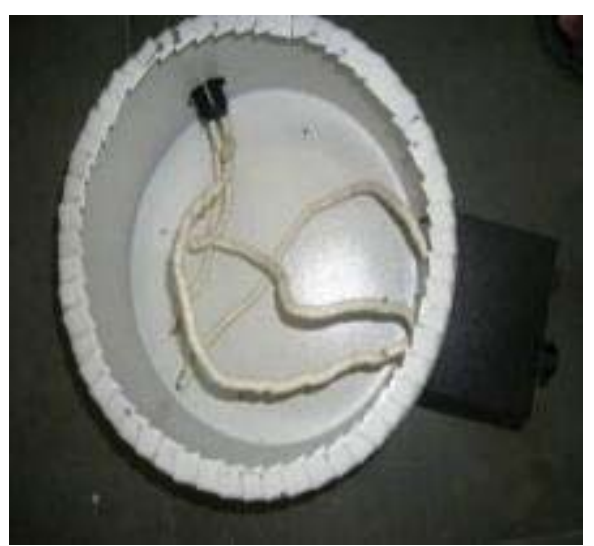

(b)

\subsubsection{Kaizen 2}

- Objective: to improve working conditions, to get a rise in production of the company.

- Problems: ergonomically not correct sitting table, caused fatigue to the worker, results in low production.

- Problem analysis: early chances of fatigue due to poor ergonomics.

- Root cause: working table height should be improved. 
- Action: ergonomically correct work tables result in rise in production and no fatigue to the worker.

- Benefits: rise in the production of the company, no early fatigue to the worker and safer work environment.

Figure 7 (a) Wrong table height (before) (b) Improved table height (after) (see online version for colours)

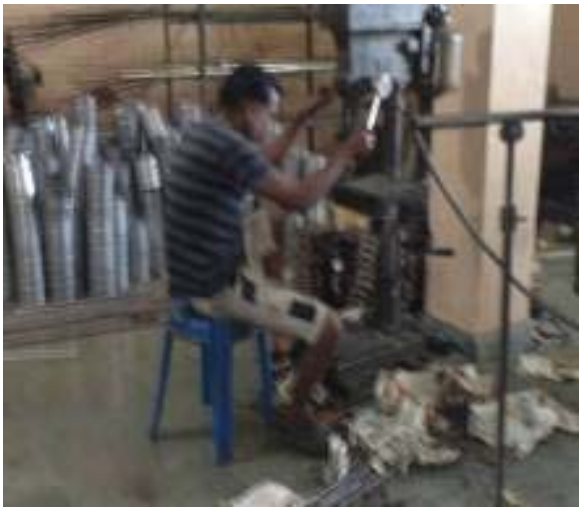

(a)

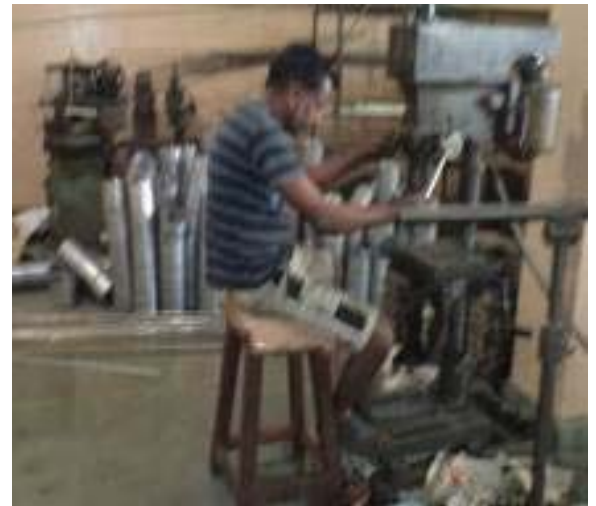

(b)

\subsubsection{Kaizen 3}

- Objective: there should be no material on shop floor.

- Problem: materials get dirty, chances of rusting increases, dirty floor.

- Problem analysis: no bin or rack offered to put the material.

- Root cause: workers are not trained in housekeeping.

- Action: there should be clean floor and dirt free environment.

- Benefits: safety of worker increased and chances of short circuiting reduced.

Figure 8 (a) Material on floor (before) (b) Material in bins (after) (see online version for colours)

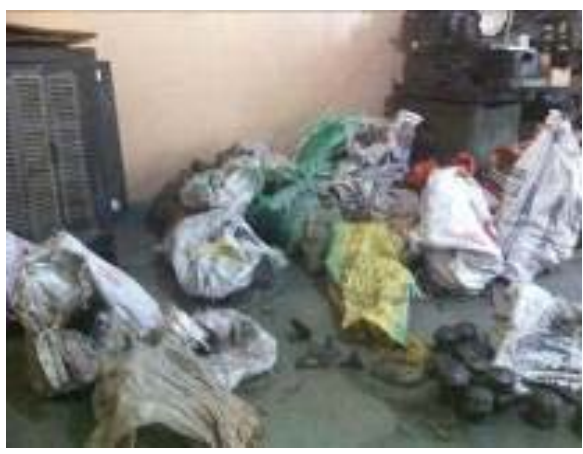

(a)

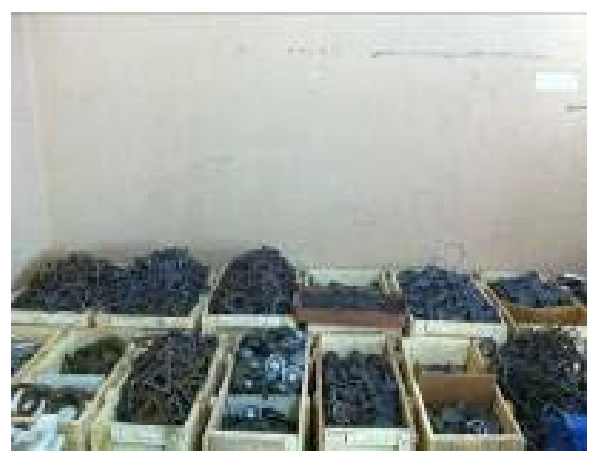

(b) 


\subsubsection{Kaizen 4}

- Objective: to avoid spreading of chip in working area so that the chance of injury reduced

- Problem: the chips removed while machining is spread so far that they reaches to the next machine and these also fed to workers that cause physical harm in the form of body injury and the chips which falls on the next machine causes some type of interruption in that machining and sometimes these chips spread so worst on the floor even some chances of accident occurs.

- Problem analysis: cuts, bleeding and eye injury of workers due to chips hit.

- Root cause: no sheet cover on any machines.

- Action: provide sheet cover.

- Benefits: workers physical safety increased and cleanliness in machine shop increased.

Figure 9 (a) No sheet cover for protection (before) (b) Sheet cover for protection (after) (see online version for colours)

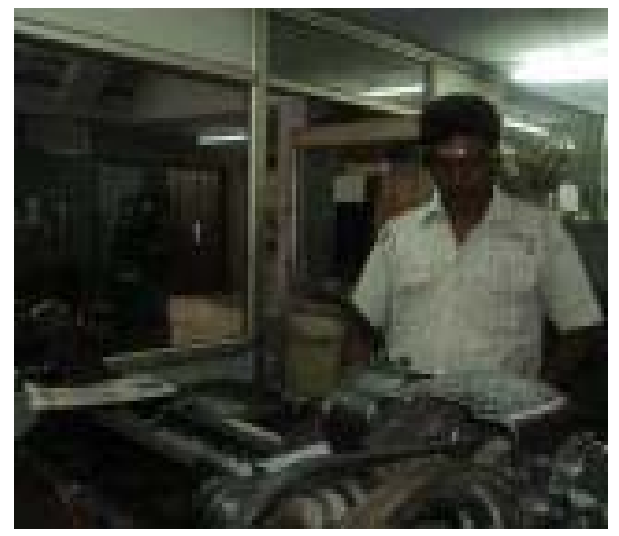

(a)

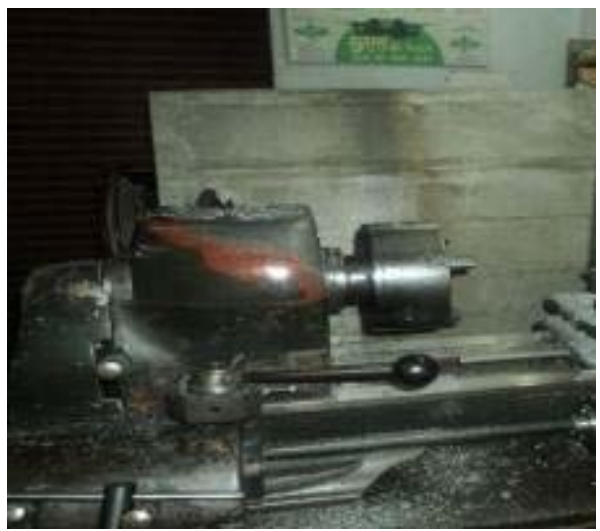

(b)

\subsubsection{Kaizen 5}

- Objective: save the time and distance travelled of workers.

- Problem: high physical movement in the process.

- Problem analysis: string diagram is made to analyse the problem.

- Root cause: problem in layout.

- Action: to maintain proper layout. 
Figure 10 Present layout

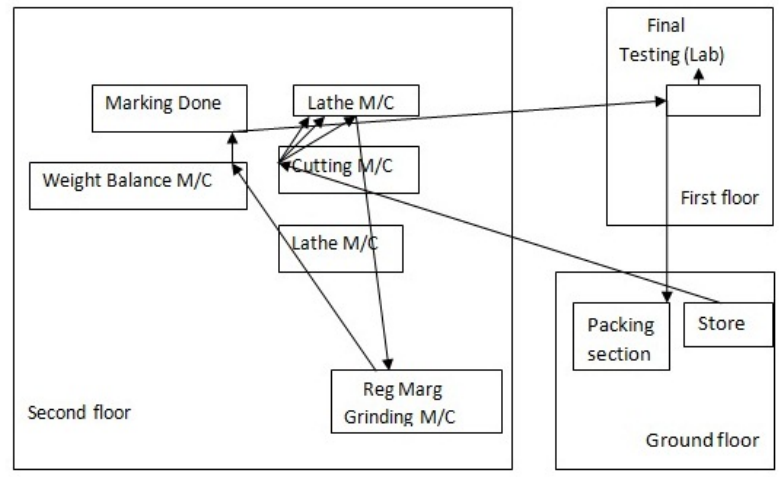

Note: Present travelling of person between diff workstations

Table 2 Present data

\begin{tabular}{lcc}
\hline Flow & Distance moved $(\mathrm{m})$ & Time taken $(\mathrm{sec})$ \\
\hline Raw material storage - cutting M/C & 20 & 80 \\
Cutting M/C - cutting on lathe & 2 & 8 \\
Cutting on Lathe - drilling on lathe & - & - \\
Drilling on Lathe - tapering on lathe & - & - \\
Tapering on Lathe - Reg-Marg grinding M/C & 50 & 200 \\
Reg-Marg grinding M/C - weight balance M/C & 48 & 192 \\
Weight balance M/C - marking table & 2 & 8 \\
Marking table - final testing & 10 & 40 \\
Final testing - packing & 10 & 40 \\
\hline Total & 142 & 568 \\
\hline
\end{tabular}

Note: Distance moved and time taken between different workstations.

Figure 11 Proposed layout

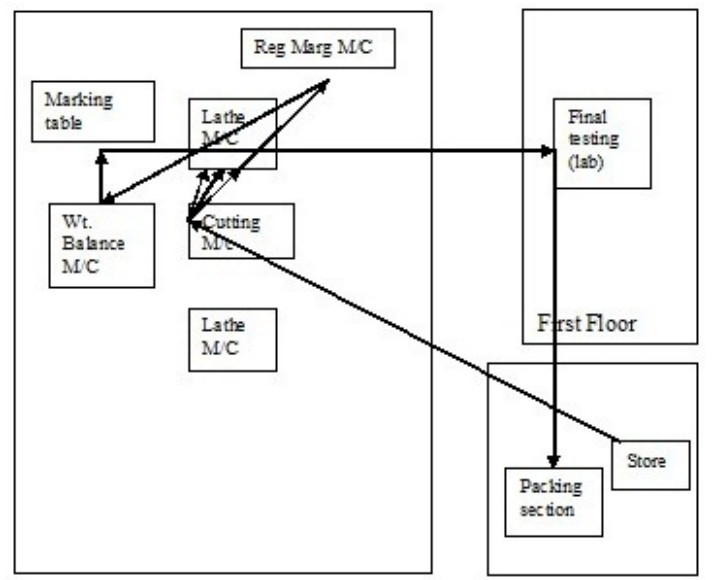

Note: Travelling of person between different work stations 
Table 3 Proposed data

\begin{tabular}{lcc}
\hline Flow & Distance moved $(\mathrm{m})$ & Time taken $(\mathrm{sec})$ \\
\hline Raw material storage - cutting M/C & 20 & 80 \\
Cutting M/C - cutting on Lathe & 2 & 8 \\
Cutting on lathe - drilling on lathe & - & - \\
Drilling on lathe - tapering on lathe & - & - \\
Tapering on lathe - Reg-Marg grinding M/C & 2 & 8 \\
Reg- Marg grinding M/C - weight balance M/C & 4 & 32 \\
Weight balance M/C - marking table & 2 & 8 \\
Marking table - final testing & 10 & 40 \\
Final testing - packing & 10 & 40 \\
\hline Total & 50 & 216 \\
\hline
\end{tabular}

Note: Distance moved and time taken between different workstations.

After analysis it is clear that there is need of change in layout. Reg-Marg Grinding Machine has to bring close to other machines to reduce movement of worker and thereby reducing wastage of time and distance. Following data is made by above analysis.

Table 4 Before and after comparison of time and distance

\begin{tabular}{lcc}
\hline Parameter & Before & After \\
\hline Total distance moved $(\mathrm{m})$ & 142 & 50 \\
Total time taken $(\mathrm{sec})$ & 568 & 216 \\
\hline
\end{tabular}

Figure 12 Distance comparison (see online version for colours)

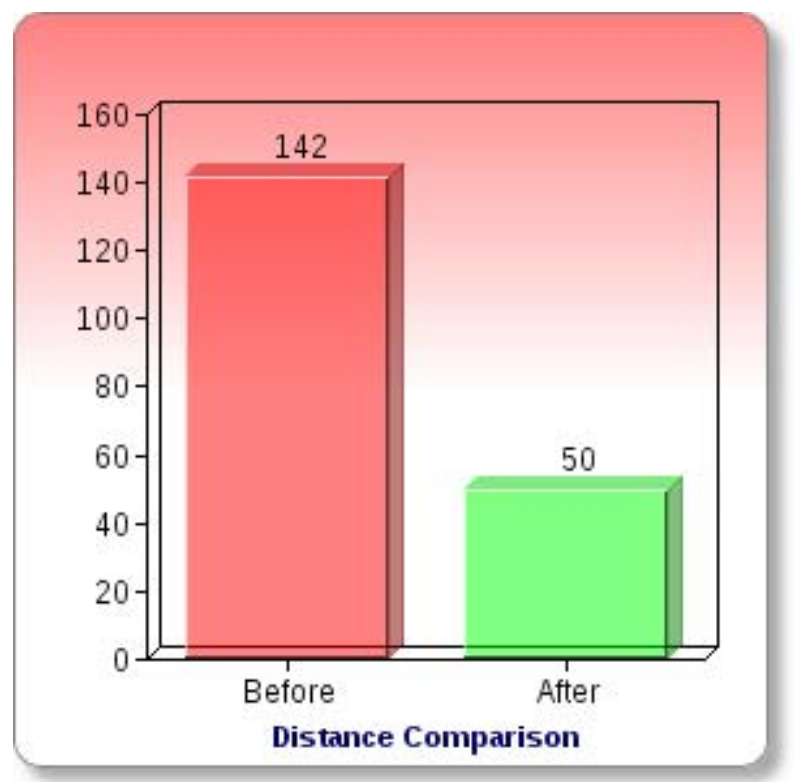


Figure 13 Time comparison (see online version for colours)

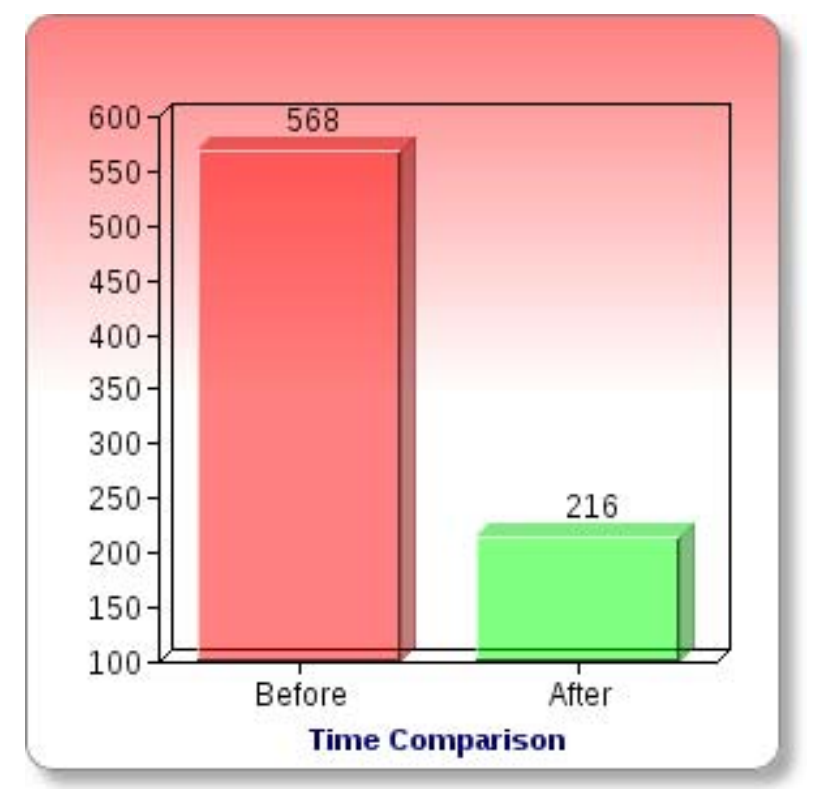

\section{Conclusions}

5S and kaizen implementation is very easy because no difficult terminologies are present. They are logical, simple and natural to human behaviour. 5S and kaizen should not be considered as a house keeping exercise. For achieving potential benefits from it one should develop a habit of not blaming people. 5S and kaizen implementation cannot be achieved if we are forcing people to work harder and faster. In order to make successful $5 \mathrm{~S}$ and kaizen system most important factors are participation, commitment and support from top level management. By implementing first ' $S$ ' first change seen will be unwanted items are eliminated and searching time is reduced. Thereby there is improved working environment and space utilised is maximised. Implementing 2 nd ' $S$ ' results in easy storage and retrieval of the items. There is a place for everything which prevents misplacing. 3rd ' $\mathrm{S}$ ' helps in having a clean, safer environment and making good impression on the visitors. Implementing 4 th ' $S$ ' will ensure better workplace standards and visual control systems. Development of team spirit and discipline can achieved by implementing 5th ' $\mathrm{S}$ '. Implementing kaizen events presumes a practical approach and low cost of improvement. Kaizen found problems as a opportunity to improve. Kaizen creates a atmosphere where employee suggestions are valued. Work gets easier in the companies where kaizen events are regularly done. Work environment becomes more enjoyable resulting in job satisfaction of the employee and higher employee morale. Kaizen activities enrich the work experience and bring out the best in every person. 


\section{References}

Asada, T., Bailes, J.C. and Suzuki, K. (2000) Implementing ABM with Hoshin Management, Institute of Management Accountants Publ., New Jersey.

Ashmore, C. (2001) 'Kaizen and the art of motorcycle manufacture', Manufacturing Engineer, Vol. 80, No. 5, pp.220-222.

Becker, J. (2001) 'Implementing 5S: to promote safety \& housekeeping', Professional Safety, Vol. 46, No. 8, pp.29-34.

Bingham, B. (2011) The Kaizen Method to Living a Healthy Lifestyle: Easy Steps to Better Eating and Exercise Habits to Help You Lose Weight and Feel Great, E-Kindle, Amazon.

Brunet, P. (2000) 'Kaizen in Japan', Understanding to Action, Vol. 1, No. 35, pp.1-10, IEE (Institute of Electrical Engineers) Seminar, Kaizen, London, UK.

Chapman, C. (2005) 'Clean house with lean 5S', Quality Progress, Vol. 38, No. 6, pp.27-32.

Chen, J.C., Dugger, J. and Hammer, B. (2000) 'A kaizen based approach for cellular manufacturing design: a case study', Journal of Technology Studies, Vol. 27, No. 2, pp.19-27.

Cheser, R.N. (1998) 'The effect of Japanese Kaizen on employee motivation in US manufacturing', International Journal of Organizational Analysis, Vol. 6, No. 3, pp.197-212.

Cooney, R. (2002) 'Is 'lean' a universal production system? Batch production in the automotive industry', International Journal of Operations \& Production Management, Vol. 22, No. 10, pp.1130-1147.

Deming, W.E. (1995) The New Economics for Industry Government and Education, 2nd ed., MIT Press, Cambridge, MA.

Deniels, R.C. (1995) 'Performance measurement at sharp and driving continuous improvement on the shop floor', Engineering Management Journal, Vol. 5, No. 5, pp.211-214.

Deniels, R.C. (1996) 'Profit-related pay and continuous improvement: the odd couple', Engineering Management Journal, Vol. 6, No. 6, pp.233-236.

Doolen, T.L., June, W.Q., Akan, V., Eileen, M. and Farris, J.A. (2003) 'Development of an assessment approach for Kaizen events', Proceedings of the 2003 Industrial Engineering and Research Conference, CD-ROM.

Dudek-Burlikowska, M. (2006) 'Quality research methods as a factor of improvement of preproduction sphere', Journal of Achievements in Materials and Manufacturing Engineering, Vol. 18, Nos. 1-2, pp.435-438.

Eileen, M., Aken, V., Farris, J.A., Glover, W.J. and Letens, G. (2010) 'A framework for designing, managing, and improving Kaizen event programs', International Journal of Productivity and Performance Management, Vol. 59, No. 7, pp.641-667.

Erlandson, R.F., Noblett, M.J. and Phelps, J.A. (1998) 'Impact of Poka-Yoke device on job performance of individuals with cognitive impairments', IEEE Transactions on Rehabilitation Engineering, Vol. 6, No. 3, pp.269-276.

Farris, J.A. (2006) An Empirical Investigation of Kaizen Event Effectiveness Outcomes and Critical Success Factors, $\mathrm{PhD}$ dissertation, Virginia Polytechnic Institute and State University.

Friedli, D. (1999) 'UK firms may suffer from kamikaze kaizen strategy', The Engineer.

Gao, S. and Low, S.P. (2013) 'Understanding the application of Kaizen methods in construction firms in China', Journal of Technology Management in China, Vol. 8, No. 1, pp.18-33.

Gapp, R., Fisher, R. and Kobayashi, K. (2008) 'Implementing 5S within a Japanese context: an integrated management system', Management Decision, Vol. 46, No. 4, pp.565-579.

Gibb, A. and Davies, L. (1990) 'In pursuit of frameworks for the development of growth models of the small business', International Small Business Journal, Vol. 9, No. 1, pp.15-31.

Gunasekran, A. and Lyu, J. (1997) 'Implementation of just in time in a small company', Production Planning and Control, Vol. 8, No. 4, pp.406-412.

Harrington, H.J. (2000) Business Process Improvement: The Breakthrough Strategy for Total Quality, Productivity, and Competitiveness, McGraw-Hill Inc., New York 
Ho, S.K., Cicmil, S. and Fung, C.K. (1995) 'The Japanese 5-S practice and TQM training', Training for Quality, Vol. 3, No. 4, pp.19-24.

Ho, S.K.M. (1997) 'Workplace learning: the 5S way', J. Workplace Learn, Vol. 19, No. 6, pp.185-191.

Ho, S.K.M. (1999a) '5s practice: the first step towards total quality management', Total Quality Management, Vol. 10, No. 3, pp.345-356.

Ho, S.K.M. (1999b) 'Japanese 5-S-where TQM begins', TQM Magazine, Vol. 11, No. 5, pp.311-320.

Ho, S.K.M. (1999c) 'The 5S auditing', Manage. Audit. J., Vol. 14, No. 6, pp.294-302.

Hongming, H., Sun, H. and Xu, Y. (2000) 'An empirical study on quality management practices in Shinghai manufacturing industries', Total Quality Management, Vol. 11, No. 8, pp.1111-1122.

Hough, D. (2008) '5S implementation methodologies', Management Services, Vol. 52, No. 2, p.44.

Hough, R. (1998) '5S: implementation methodology', Management Service, Vol. 2, No. 1, pp.44-48.

Hubbard, R. (1999) 'Case study on the 5S program: the five pillars of the visual workplace', Hospital Material Management Quarterly, Vol. 20, No. 4, pp.24-28.

Imai, M. (1986) Kaizen: 'The Key to Japan's Competitive Success', Random House Published, New York.

Imai, M. (2008) Gemba Kaizen. A Commonsense, Low-Cost, Approach to Management, Kaizen Institute, Warsaw.

Irane, Z. and Sharp, J.M. (1997) 'Integrating continuous improvement and innovation into a corporate culture: a case study', Technovation, Vol. 17, No. 4, pp.225-226.

Korkut, D.S., Cackicier, N., Erdinler, E.S., Ulay, G. and Dogan, A.M. (2009) '5s activities and its application in a sample company', African Journal of Biotechnology, Vol. 8, No. 8, pp.1720-1728.

Kraszewski, R. (2005) Quality Management - Conceptions, Methods and Tools used by the World's Business Leaders, Scientific Society of Management Published, Torun.

Lancucki, J. (2001) Basis of Total Quality Management, AE, Poznan, (in Polish).

Lee, M. (2000) 'Customer service excellence through people motivation and Kaizen', IEE Seminar, 'Kaizen: from Understanding to Action', Vol. 5, No. 35, pp.1-21.

Malik, S.A. and YeZhuang, T. (2006) 'Execution of continuous improvement practices in Spanish and Pakistani industry: a comparative analysis', IEEE International Conference on Management of Innovation and Technology, Vol. 2, pp.761-765, Singapore.

Malik, S.A., Li-Bin, L., YeZhuang, T. and Xiao-Lin, S. (2007) 'Continuous improvement practices in Asian developing countries: a comparative analysis between Chinese and Pakistani manufacturing industry', 14th International Conference on Management Science and Engineering, pp.692-697, Harbin, China.

Mente, D. (1994) Japanese Etiquette \& Ethics in Business, NTC Business Books, Lincolnwood, IL.

Narasimhan, G. (2009) 'Strategic handling to changes in small manufacturing organizations in India', International Journal of Business and Management, Vol. 4, No. 1, pp.141-148.

Palmer, V.S. (2001) 'Inventory management kaizen', Proceedings of 2nd International Workshop on Engineering Management for Applied Technology, pp.55-56, Austin, USA.

Peterson, J. and Smith, R. (2001) The 5S Pocket Guide, Quality Resources, New York.

Pettigrew, A.M. (1990) 'Longitudinal field research: theory and practice', Organization Science, Vol. 1, No. 3, pp.267-292.

Pheng, L.S. (2001) 'Towards TQM-integrating Japanese 5-S principles with ISO 9001:2000 requirements', TQM Magazine, Vol. 13, No. 5, pp.334-341. 
Pheng, S.L. and Khoo, S.D. (2001) 'Team performance management: enhancement through Japanese 5-S principles', Team Performance Management: An International Journal, Vol. 7, Nos. 7/8, pp.105-111.

Powel, J.A. (1999) 'Action learning for continuous improvement and enhanced innovation in construction', Proceedings of IGLC-7, pp.433-444, University of California, USA.

Radharamanan, R., Godoy, L.P. and Watanabe, K.I. (1996) 'Quality and productivity improvement in a custom-made furniture industry using kaizen', Computer and Industrial Engineering, Vol. 31, Nos. 1/2, pp.471-474.

Reid, R.A. (2006) 'Productivity and quality improvement: an implementation framework', International Journal of Productivity and Quality Management, Vol. 1, Nos. 1/2, pp.26-36.

Saraph, J., Benson, G. and Schroeder, R. (1989) 'An instrument for measuring the critical factors of quality management', Decision Sciences, Vol. 20, No. 4, pp.457-478.

Sethi, G. and Pal, P. (1995) Energy Efficiency in Small Scale Industry - An Indian Perspective, 64p, TERI (Tata Energy Research Institute), New Delhi, India.

Sevim, K.D. (2005) Total Maintenance Management and Application in a Forest Products Enterprise, $\mathrm{PhD}$ thesis, Istanbul University, Institute of Science, Istanbul, Turkey.

Sharrock, R. (2007) 'Rub maker revitalizes', Industrial Engineering, Vol. 1, No. 3, pp.50-51.

Sheridan, J.H. (1997) 'Kaizen Blitz’, Industry Week, Vol. 246, No. 16, pp.18-27.

Soderquist, K. (1996) 'Managing innovation in SMES: a comparison of companies in UK, France and Portugal', International Journal of Technology Management, Vol. 12, No. 3, pp.291-305.

Suárez-Barraza, M.F., Ramis-Pujol, J. and Dahlgaard-Park, S.M. (2013) 'Changing quality of life through the Personal Kaizen approach: a qualitative study', International Journal of Quality and Service Sciences, Vol. 5, No. 2, pp.191-207.

Suárez-Barraza, M.F., Ramis-Pujol, J. and Estrada-Robles, M. (2012) 'Applying Gemba-Kaizen in a multinational food company: a process innovation framework', International Journal of Quality and Service Sciences, Vol. 4, No. 1, pp.27-50.

Suárez-Barraza, M.F., Ramis-Pujol, J. and Sándoval-Arzaga, F. (2011) 'Finding kaizen approach in small Mexican family businesses: an exploratory study', Journal of Family Business Management, Vol. 1, No. 2, pp.107-129.

Suzaki, K. (1987) The New Manufacturing Challenge-Techniques of Manufacturing Systems, John Wiley and Sons, Inc., New York.

Suzuki, H. (1993) Practical Kaizen for Productivity Facilitators, Japan Productivity Center Published, Tokyo.

Vasudevan, A. (1998) 'Perspective of the role of small scale industries in India's economic development', Reserve Bank of India Bulletin, Vol. 3, No. 10, pp.8-28.

Watanabe, R.M. (2011) 'Getting ready for kaizen: organizational and knowledge management enablers', VINE, Vol. 41, No. 4, pp.428-448.

Wickens, P.D. (1990) 'Production management: Japanese and British approaches', IEE Proceedings Science, Measurement and Technology, Vol. 137, No. 1, pp.52-54.

Williamson, A. (1997) 'Target and kaizen costing', Manufacturing Engineer, Vol. 76, No. 1, pp.22-24. 